\title{
ANNUAL ABOVEGROUND PRODUCTION AND CONSUMPTION BY LARGE MAMMALIAN HERBIVORES IN THE NORTHERN RANGE OF YELLOWSTONE NATIONAL PARK
}

\author{
Douglas A. Frank \\ S. J. McNaughton \\ Biological Research Laboratories \\ Syracuse University \\ syracuse
}

\section{objectives}

The principal objectives of this study are to measure aboveground net primary productivity and consumption by large mammalian herbivores in Yellowstone's northern range. The significance of such information is two-fold. Firstly, it will provide a "pulse rate" of ecosystem processes in an integral region of the Yellowstone Ecosystem and a comparison of rates of energy and nutrient flows with other ecosystems worldwide. This is of particular ecological interest, since such data for areas supporting large populations of freeranging native herbivores are rare. Secondly, these data will provide a greater understanding of the effects of ungulate use on ecosystem function in Yellowstone, and thereby, an assessment of current park management of ungulate populations.

\section{Methods}

Because of the expansiveness of the northern range, subsampling was required. The following 11 plant communities were sampled in 1988 and 1989:
Winter Range
a) Xeric graminoid (Crystal Bench)
b) Brome-dominated graminoid (Lamar Valley)
c) Timothy-dominated graminoid (Lamar Valley)
Transitional
Range
a) Xeric graminoid ridgetop
b) Sagebrush-graminoid slope
c) Mesic graminoid swale
Summer Range
a) Xeric graminoid ridgetop
b) Sagebrush-graminoid slope
c) Mesic graminoid meadow
d) Mesic forb-graminoid meadow
e) Lodgepole pine understory 
Standing crop was estimated using canopy intercept, a calibrated method that relates standing biomass to the number of contacts a pin makes when passed through vegetation at a fixed angle. This technique provides high precision to reasonably estimate standing crop, although attention should be given to selecting appropriate regression equations for species of different growth forms (Frank and McNaughton 1990).

Standing crop was measured inside and outside small, movable exclosures every four weeks, from snowmelt to snowfall in each community. In addition, peak standing crop was measured inside large, permanent exclosures (three replicates per community) in two communities in 1988, and four communities in 1989. Aboveground plant production (APP) in grazed vegetation will be calculated as the sum of the statistically significant positive increments of standing crop inside small exclosures during sampling intervals. Total consumption will be calculated as the sum of significant differences inside versus outside small exclosures. Values for peak biomass inside permanent exclosures, estimates of APP in ungrazed vegetation, will be compared to those values for grazed vegetation to explore the impact of ungulates on energy and nutrient fluxes to aboveground plant structures.

Fecal deposition was estimated in each site with $10,2 \times 10 \mathrm{~m}$ transects. Fecal biomass was calculated as the number of fecal piles multiplied by the average fecal biomass for each ungulate species. Using allometric relationships for ungulate body size, these data will enable us to estimate the flow of nutrients from ungulates to soil organisms and plants.

\section{$\underline{\text { Results }}$}

Currently, results for 1988 and 1989 are too preliminary to formalize in a report. However, we plan to explore several functional attributes of the northern range. The following are the most notable:

1) Aboveground primary production

2) Consumption

3) Consumption on APP

4) Percent consumption on APP

5) Consumption on nutrient return by ungulates 
6) Plant species diversity on APP

7) Plant species diversity on consumption

of course, the enormous differences in climate and ungulate numbers between 1988 and 1989 will enable us to determine a substantial extent of the potential variation of these processes for the northern range. Large ANOVAs that include grazing, date, and year as treatments are being performed on species, species group and total biomass data for each of the communities. This should place us in a good position for a timely completion of the project.

\section{Literature Cited}

Frank, D. A. and S. J. McNaughton. 1990. Aboveground biomass estimation using the canopy intercept method: a plant growth form caveat. Oikos 1990 (in press). 